\author{
Kristian Oentoro ${ }^{1}$ dan Bernike Elsafany \\ Program Studi Desain Produk \\ FAD, Universitas Kristen Duta Wacana \\ 1kristian@staff.ukdw.ac.id
}

\title{
PENGEMBANGAN DESAIN FURNITUR ANAK BERBAHAN KERTAS SEMEN BEKAS DENGAN TEKNIK LAMINASI \& SPIRAL WOUND TUBING
}

\begin{abstract}
Abstrak. Semen merupakan salah satu bahan utama untuk mendirikan sebuah bangunan, penggunaannya semakin hari semakin banyak seiring dengan pembangunan di berbagai wilayah di Indonesia. Tumpukan kertas semen bekas yang mudah ditemui di lingkungan sekitar juga belum banyak dimanfaatkan menjadi produk fungsional, sehingga usia pakainya tergolong singkat. Padahal kualitas dan karakteristiknya lebih baik daripada kertas bekas lain, khususnya dalam hal menahan beban. Melalui penelitian desain berbasis eksporasi bahan ini, kertas semen bekas dapat dikembangkan menjadi furnitur anak yang ergonomis dengan desain terinspirasi bentuk hewan (gajah). Teknik utama yang diaplikasikan dalam pengembangan desain ini adalah laminasi \& spiral wound tubing, aplikasi kedua teknik ini termasuk inovatif karena umumnya pemanfaatan kertas semen bekas dalam produk kerajinan hanya dengan teknik pilin dan anyam. Metode penelitian desain yang digunakan melalui 3 tahap utama, yakni identifikasi, visualisasi dan materialisasi ide berdasarkan optimalisasi karakteristik materialnya (Ashby, 2010). Berdasarkan hasil eksplorasi material dan teknik pada kertas semen bekas, karakteristik yang menonjol adalah ringan dan kokoh. Selain itu, penelitian pengembangan desain ini juga bertujuan untuk meningkatkan nilai komersial kertas semen bekas dan membuka peluang baru dalam berbagai pengembangannya, khususnya aplikasi pada produk-produk struktural. Hasil dari penelitian ini menunjukan bahwa teknik laminasi dan spiral wound tubing layak diaplikasikan menjadi material furnitur anak, serta aman dan nyaman dipakai untuk anak berdasarkan hasil uji coba.
\end{abstract}

Kata kunci : kertas semen, laminasi, spiral wound tubing, furnitur anak.

Abstract. Cement is one of the main materials to construct a building; its use is increasing day by day along with the development in various regions in Indonesia. A stack of used cement paper easily found in the environment is still not widely utilized as a functional product, therefore the age of use is relatively short. Even though, its quality and characteristic is better than other waste papers, especially in term of holding load. Through this material-exploration-based research design, waste cement paper can be developed to be ergonomic children furniture with the design inspired by animal shape (elephant). The main technique applied in this design development is lamination \& spiral wound tubing, both application included innovative because generally the utilization of waste cement paper in craft products only applied by spiral and wicker technique. The method of research design which is used through three main steps; those are identification, visualization, and idea materialization based on its material characteristics optimization (Ashby, 2010). According to the result of material exploration and technique in used cement paper, the prominent characteristics are light and sturdy. Furthermore, this design development research also aimed to increase commercial value of waste cement paper and to open new opportunity in its various developments, especially the application of structural products. The findings of this research show that lamination technique and spiral wound tubing is appropriate to be applied as children furniture material, and safe and comfortable to be used by children according to test result.

Keyword: cement paper, lamination, spiral wound tubing, children furniture 


\section{Pendahuluan}

Hampir setiap proyek pembangunan fisik memerlukan semen sebagai salah satu material utama dan menyisakan tumpukan kantong kertas semen bekas. Berdasarkan hasil wawancara, dalam setiap proyek pembangunan gedung di Yogyakarta rata-rata menghabiskan 7.000 kantong kertas semen bekas per-tahun, khususnya dalam tahap konstruksi. Biasanya kantong kertas semen bekas pakai dijual ke pemulung dan beberapa disimpan untuk menghaluskan lapisan semen terakhir pada tembok. Kantong kertas semen bekas umumnya dijual dengan harga 3-5 ribu rupiah per kilogram, harganya akan lebih mahal jika dijual dalam keadaan bersih. Sedangkan dari segi inovasi pemanfaatannya masih minim, padahal kualitas material kertas semen bekas dalam hal kekuatan dan kepadatan tergolong paling bagus daripada kertas-kertas bekas lainnya karena mampu menahan beban $40 \mathrm{~kg} / \mathrm{sak}$ semen.

Berdasarkan data Asosiasi Pulp dan Kertas Indonesia pada tahun 2014, Indonesia merupakan produsen pulp dan kertas terbesar di ASEAN. Industri pulp menempati urutan ke-9 dan industri kertas menempati urutan ke 11 di dunia (APKI, 2016:9). Selain digunakan untuk kebutuhan baca tulis, kebutuhan lain yang cukup besar dari material kertas adalah untuk kemasan. Kertas semen atau disebut kertas kraft (craft sack paper) tergolong jenis kertas industri, kegunaan utamanya adalah sebagai kertas bungkus (wrapping), kantong (bag/sack) dan karung (shipping sack). Sedangkan bahan baku yang umum digunakan dalam produksi kertas kraft adalah jenis kayu lunak karena mengandung banyak serat selulosa dan hemiselulosa, seperti kayu pinus (Muladi, 2001). Tingginya jumlah produksi kertas kraft ini juga tidak sebanding dengan usia pakainya, khususnya keperluan kemasan yang rata-rata hanya dipakai satu kali saja.
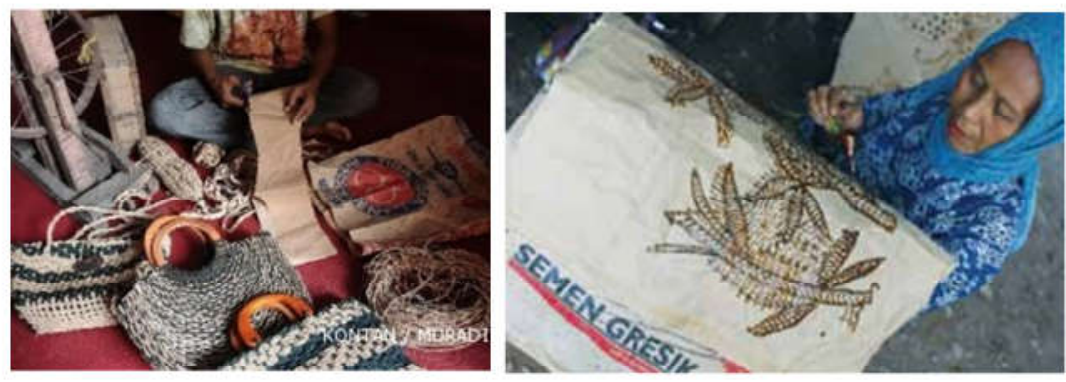

Gambar 1.1. Berbagai pengolahan kerajinan kertas kantong semen bekas

Sumber : www.kontan.co.id

Di Indonesia, pemanfaatan kertas semen bekas menjadi sebuah produk fungsional masih terbatas pada teknik olah yang biasanya dikerjakan dengan teknik pilin dan anyam seperti 
produk-produk kerajinan pada umumnya. Sebagian besar produk berfungsi sebagai produk pakai (wearable product) seperti tas, dompet, sandal, bahkan ada yang memproduksi batik di atas kertas semen. Berdasar hasil obervasi, peminatnya cukup banyak namun produk-produk pakai berbahan bekas terkadang jarang dipakai oleh konsumen karena kurang sesuai dengan tren pasar atau busana. Dengan melihat fenomena tersebut, maka diperlukan inovasi desain produk berbahan kertas semen bekas melalui eksplorasi teknik olah baru dan aplikasinya pada jenis produk fungsional yang lain, dalam penelitian ini adalah desain produk furnitur khususnya untuk anak-anak.

Desain furnitur anak dipilih karena berdasarkan hasil studi awal terhadap kekuatan laminasi dan spiral wound tubing kertas semen hanya mampu menahan beban hingga 50kg dengan sempurna, sehingga anak-anak merupakan segmen yang lebih tepat menjadi pengguna produk. Pengembangan desain furnitur anak memiliki tantangan selain dalam hal kekuatan konstruksi, juga bagaimana menarik minat anak sehingga nyaman dan aman ketika memakai. Sedangkan dari segi pasar produk, sarana belajar di lembaga pendidikan anak-anak memerlukan inovasi yang lebih inspiratif dengan desain dan bahan yang unik. Penelitian pengembangan desain ini bertujuan untuk menemukan konfigurasi bentuk dan konstruksi yang optimal sebagai sebuah furnitur anak berbasis kertas semen bekas. Sedangkan manfaat dari hasil penelitian ini dapat membuka inspirasi dan peluang pengembangan berbagai desain furnitur berbahan kertas semen bekas dengan aplikasi teknik laminasi dan spiral wound tubing.

\section{Kajian Literatur}

Beberapa penelitian terdahulu yang berkaitan dengan pemanfaatan kertas semen bekas banyak menerapkan teknik komposit, yakni penggabungan antara dua atau lebih unsur yang berbeda atau tidak dapat dilarutkan satu sama lain guna menghasilkan bahan baru (Saragi, 2008:1). Dalam penelitiannya kertas semen dilebur dicampur dengan pulp jerami untuk menghasilkan jenis kertas baru. Sedangkan penelitian Sihombing pada tahun 2009 memanfaatkan kertas semen bekas sebagai limbah padat menjadi agregat dalam batako ringan. Dari kedua penelitian tersebut, aspek yang menjadi pembeda dengan penelitian ini adalah teknik olah kertas semen yang tidak melebur kertas atau merusak susunan serat kertas semen sehingga proses pembahanan lebih dapat dilakukan dengan cara dan peralatan yang sederhana. Berikut ini adalah kajian terkait dengan pengembangan desain furnitur anak berbahan kertas semen bekas dengan teknik laminasi dan spiral wound tubing.

\subsection{Kertas Semen (sack kraft paper)}

Kertas merupakan material yang berbentuk tipis dan rata. Kertas dihasilkan melalui kompresi serat yang berasal dari bubur kertas ( pulp) dan ditambah dengan bahan pelengkap lainnya. Serat yang terkandung dalam kertas merupakan serat selulosa dan hemiselulosa 
(Saragi,2008:6). Salah satu jenis kertas yang banyak diproduksi adalah kertas semen (sack kraft paper), total produksinya di Indonesia dapat mencapai 135.000 ton per tahun (kka.co.id). Jenis kertas ini juga dapat digunakan untuk mengemas barang-barang besar dan berat seperti produkproduk semen, pupuk dan agribisnis karena memiliki kualitas dan kekuatan yang tinggi. Menurut Atnam (2007), gramatur kertas semen berkisar antara 50-134 gsm serta tidak mengalami proses bleaching, sehingga berwarna coklat. Kertas ini juga dikenal sebagai kertas samson. Secara umum, kertas semen mempunyai 3 kegunaan utama :

a. Kertas bungkus (wrapping), umumnya untuk membungkus kertas plano, kertas bungkus nasi dan pembungkus lainya.

b. Kantong ( $\mathrm{bag} / \mathrm{sack})$, seperti kantong belanja atau 'shopping bag'.

c. Karung (shipping sack), digunakan untuk karung atau kantong semen dan berbagai fungsi 'covering'.

\subsection{Teknik Laminasi \& Spiral Wound Tubing}

Teknik laminasi banyak diaplikasikan pada material kayu yang dikenal dengan papan lamina, yakni papan yang digabungkan dengan perekat serta diberi tekanan dingin untuk menguatkan ikatan antar papan (Handayani, S. 2009). Sedangkan teknik spiral wound tubing, memiliki prinsip yang hampir sama dengan laminasi namun berbentuk pipa. Kedua teknik tersebut merupakan sebuah rekayasa dalam proses perekatan antara dua atau lebih lembaran guna meningkatkan kekuatan dalam menahan beban. Menurut Walker (2006), teknik ini mampu menghasilkan ukuran papan yang lebar dan panjang sesuai dengan kebutuhan tanpa harus berpikir tentang penyambungan.

Pada umumnya papan lamina dapat digunakan untuk pembuatan lemari, meja, kursi, lantai dan berbagai macam furnitur lainnya. Adapun dua jenis laminasi yang banyak diterapkan pada lembaran kayu adalah :

a. Laminasi tekanan panas (hot press)

Biasanya laminasi dengan tekanan panas dilakukan untuk plywood menggunakan bahan baku softwood dengan suhu mencapai $120{ }^{\circ} \mathrm{C}$ yang mendapat panas dan tekanan selama hampir 10 menit.

b. Laminasi dingin (cold press)

Laminasi dingin dilakukan dengan alat tekan hidrolik atau putar. Jenis lem yang digunakan biasanya adalah resin atau urea-formaldehyde yang memiliki proses pengeringan lebih lama. Proses pemberian tekanan pada lembaran dilakukan selama 4 hingga 24 jam. 
Sedangkan spiral wound tubing merupakan teknik menggulung lembaran (kertas) yang disusun dengan teknik silang setiap lapisnya. Pada umumnya teknik ini diaplikasikan dalam pembuatan paper tube yang merupakan tabung/gulungan berbahan kertas, biasanya ini digunakan sebagai inti gulungan benang, kain, kawat logam plastik film, kertas, dan lain-lain. Spesifikasi dari paper tube ditentukan dari dimensi, yaitu diameter dalam (inside diameter), diameter luar (outside diameter), panjang tabung dan kuat tekan tabung kertas itu sendiri (Leonel, 2008:45). Di samping itu, kekuatan paper tube terhadap tekanan sangat tergantung pada tumpuan (overlapping) strip/spiral yang digunakan. Jika seluruh strip kertas menumpuk pada satu bagian/ tidak ada overlapping, maka tidak akan membentuk paper tube dan hanya berbentuk spiral saja.

\subsection{Furnitur Anak}

Desain furnitur untuk anak memiliki kriteria persyaratan tersendiri yang berbeda dari kriteria persyaratan furnitur untuk orang dewasa. Menurut Gegadannitisswari (2009:44), furnitur anak yang baik memiliki beberapa syarat antara lain :

a. Ukuran furnitur memenuhi standar ergonomi anak umur 3-6 tahun

b. Furnitur anak tidak memiliki bentuk tajam atau membahayakan, sebaiknya bentuk lengkung dan sudut tumpul.

c. Furnitur anak menggunakan bahan finishing yang aman, serta sedapat mungkin tidak menggunakan bahan kaca.

d. Menggunakan bahan dasar yang tidak mengandung racun atau zat kimia, tahan lama dan ringan sehingga mudah dipindahkan.

e. Desain memiliki variasi bentuk dan warna sehingga anak tidak mudah bosan.

f. Apabila memungkinkan dapat digunakan sebagai media permainan / multifungsi.

\section{Metoda Penelitian}

Metode penelitian yang digunakan adalah metode pengembangan desain berbasis eksperimen material. Sedangkan teknik olah yang digunakan dalam uji coba penelitian ini adalah teknik laminasi \& spiral wound tubing. Pemilihan kedua teknik ini didasari atas beberapa pertimbangan, antara lain proses pemanfaatan kertas semen bekas lebih mudah dikerjakan serta menggunakan peralatan yang sederhana. Selain itu, teknik pengolahan dengan tidak melebur atau merusak kandungan serat selulosa di kertas juga akan menghemat waktu dan tenaga. 


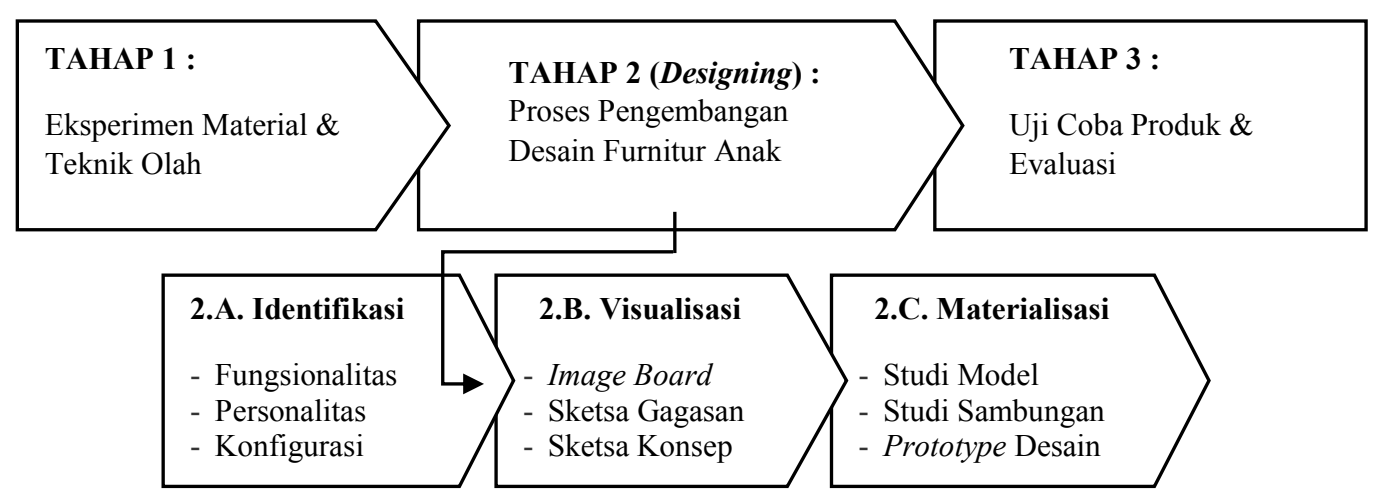

Gambar 3.1. Bagan Alur / Tahap Penelitian Desain Furnitur Anak Berbahan Kertas Semen Bekas

Langkah-langkah yang dilakukan dalam penelitian ini terbagi dalam tiga tahap utama, yaitu (1) eksperimen material \& teknik olah, (2) proses pengembangan desain furnitur anak dan (3) ujicoba \& evaluasi. Pada tahap 1 eksperimen material dilakukan serangkaian percobaan sederhana hasil laminasi dan spiral wound tubing berbahan kertas semen bekas dalam kekuatannya menahan beban serta mengetahui potensi dan karakteristiknya. Kemudian pada tahap 2, pengembangan desain furnitur anak terbagi tiga sub-tahap yakni identifikasi, visualisasi dan materialisasi (Ashby, 2010:104-120). Proses identifikasi meliputi penelusuran terhadap kebutuhan pengguna dari segi fungsionalitas dan personalitas, kemudian mencari konfigurasi bentuk dan penentuan standar ukuran. Sedangkan proses visualisasi merupakah tahap pengembangan konsep dengan menuangkan gagasan desain furnitur anak secara visual melalui image board dan sketsa gagasan. Setelah mendapatkan rancangan desain terpilih, maka dilanjutkan proses materialisasi yang merupakan proses perwujudan desain furnitur anak. Tahap akhir dalam penelitian ini adalah dengan melakukan uji coba produk kepada pengguna serta melakukan evaluasi hasil pengembangan desain.

\section{Hasil Penelitian dan Pengembangan Desain Furnitur Kertas Semen Bekas}

Langkah awal yang dilakukan sebelum melakukan eksperimen adalah tahap persiapan bahan dasar atau disebut dengan pembahanan. Kertas semen bekas yang baru dibeli dari penjual kertas bekas maupun didapat dari proyek rata-rata kusut dan kotor sisa butiran semen sehingga sebelum mengolah kertas semen bekas dengan teknik laminasi maupun spiral wound tubing diperlukan persiapan bahan agar layak diolah. Pertama terlebih dahulu membersihkan debu di kertas semen bekas dengan menggunakan kemoceng atau sikat lembut. Kemudian menghaluskan permukaannya agar mudah disusun setiap lapisnya, salah satu cara untuk menghaluskan 
permukaan kertas semen bekas adalah dengan memanaskan dan merapikan dengan menggunakan setrika listrik (Gambar 4.1.). Setelah permukaan halus, kertas semen dapat di potong-potong sesuai ukuran yang dibutuhkan.
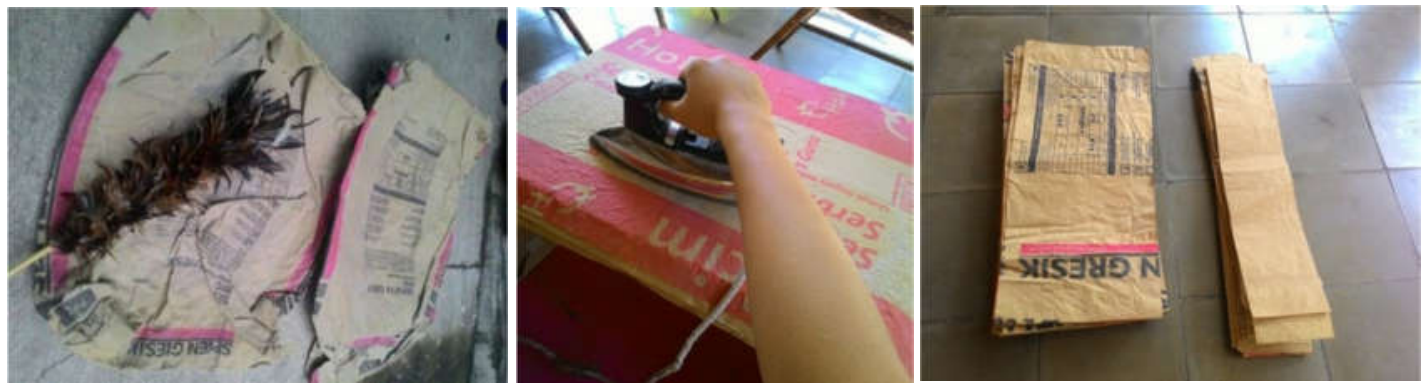

Gambar 4.1. Proses persiapan bahan kertas semen bekas sampai layak diolah Sumber : Dokumentasi Peneliti

Setelah kertas semen bekas siap diolah, maka dilakukan proses laminasi sebagai teknik pertama yang dipakai dalam eksperimen. Proses laminasi memerlukan tekanan tinggi agar susunan lembar kertas semen bekas dapat saling terikat kuat dengan menggunakan klem bentuk $\mathrm{C}$ dan klem bentuk F. Sedangkan untuk teknik spiral wound tubing memerlukan cetakan berbentuk silinder atau pipa dengan melilitkan kertas potongan memanjang dengan kemiringan $45^{\circ}$ dalam posisi serat saling silang.

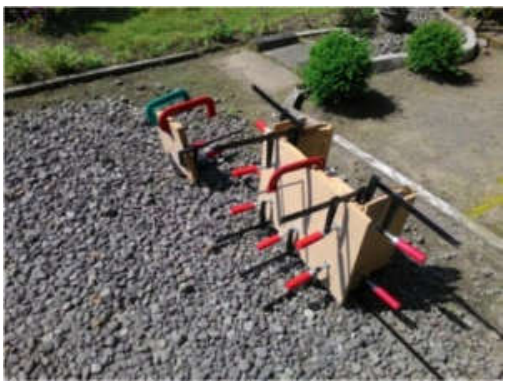

(a)

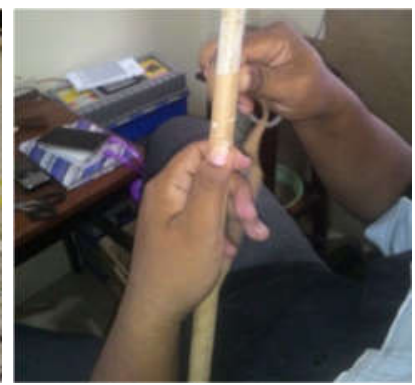

(b)

Gambar 4.2. (a) Proses laminasi kertas semen, (b) Proses spiral wound tubing Sumber : Dokumentasi Peneliti

Kedua teknik tersebut memerlukan perekat ketika menumpuk lembaran kertas semen bekas kedalam cetakan, perekat yang dipakai adalah jenis PVAc (Polyvinyl Acetate). Setelah selesai mencetak dengan sempurna, maka teknik laminasi dan spiral wound tubing memerlukan proses pengeringan selama 1-2 hari dengan bantuan sinar matahari. 


\subsection{Eksperimen Kertas Semen Bekas}

Dalam eksperimen teknik laminasi pada kertas semen bekas menggunakan dua bentuk dasar cetakan yaitu papan datar $(15 \mathrm{~cm} \times 15 \mathrm{~cm})$ dan papan melengkung $(15 \mathrm{~cm} \mathrm{x} 6 \mathrm{~cm})$. Sedangkan percobaan teknik spiral wound tubing menggunakan satu bentuk silinder atau pipa lurus (diameter $4 \mathrm{~cm}$ ) dengan panjang $25 \mathrm{~cm}$ yang diberi tekanan dalam bidang horisontal.

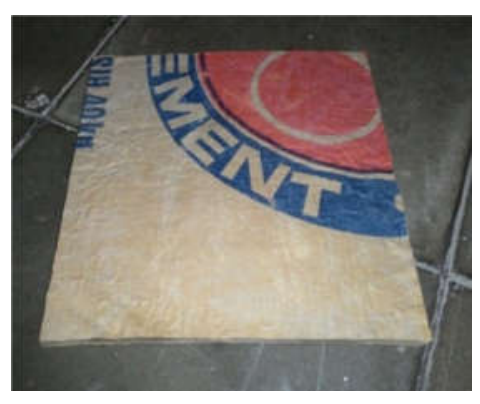

(a)

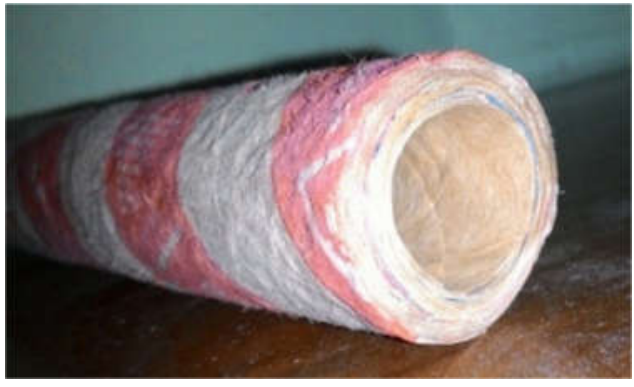

(b)

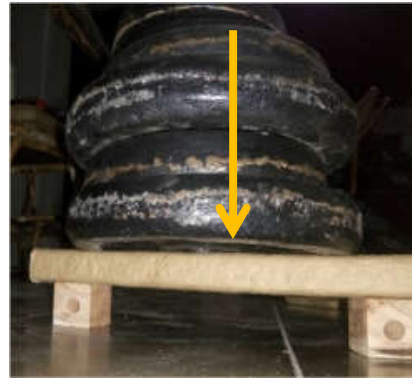

(c)

Gambar 4.3. Bahan uji coba (a) laminasi (b) spiral wound tubing \& (c) posisi pengujian beban

Sumber : dokumentasi peneliti

Melalui percobaan secara sederhana, ketiga bentuk tersebut diberikan beban berupa besi barbel dalam interval 5 kilogram. Kemudian lapisan kertas semen bekas juga ditambah ketebalannya dengan interval 10 lembar. Percobaan ini bertujuan untuk mengetahui seberapa kuat bentuk-bentuk tersebut berdasarkan ketebalannya. Di bawah ini merupakan tabel hasil uji coba kekuatan

Tabel 4.1. Hasil uji coba \& perbandingan kekuatan berdasar teknik olah kertas semen

\begin{tabular}{|c|c|c|c|c|c|c|c|c|c|c|c|c|}
\hline \multirow{2}{*}{ Teknik Olah } & \multicolumn{2}{|c|}{ Ketebalan } & \multicolumn{10}{|c|}{ Keteguhan menahan beban (kg) } \\
\hline & Lapis & Tebal & 5 & 10 & 15 & 20 & 25 & 30 & 35 & 40 & 45 & 50 \\
\hline 1. Laminasi papan & $20 \mathrm{lbr}$ & $0,3 \mathrm{~cm}$ & $\sqrt{ }$ & $\sqrt{ }$ & $\sqrt{ }$ & $\mathrm{x}$ & - & - & - & - & - & - \\
\hline bentuk datar & $30 \mathrm{lbr}$ & $0,6 \mathrm{~cm}$ & $\sqrt{ }$ & $\sqrt{ }$ & $\sqrt{ }$ & $\sqrt{ }$ & $\sqrt{ }$ & $\mathrm{x}$ & - & - & - & - \\
\hline (ukuran : $15 \mathrm{~cm} \times 15 \mathrm{~cm}$ ) & $40 \mathrm{lbr}$ & $0,9 \mathrm{~cm}$ & $\sqrt{ }$ & $\sqrt{ }$ & $\sqrt{ }$ & $\sqrt{ }$ & $\sqrt{ }$ & $\sqrt{ }$ & $\sqrt{ }$ & $\mathrm{x}$ & - & - \\
\hline 2. Laminasi papan & $20 \mathrm{lbr}$ & $0,3 \mathrm{~cm}$ & $\sqrt{ }$ & $\mathrm{X}$ & - & - & - & - & - & - & - & - \\
\hline bentuk lengkung & $30 \mathrm{lbr}$ & $0,6 \mathrm{~cm}$ & $\sqrt{ }$ & $\sqrt{ }$ & $\sqrt{ }$ & $\mathrm{x}$ & - & - & - & - & - & - \\
\hline (ukuran : $15 \mathrm{~cm} \times 6 \mathrm{~cm}$ ) & $40 \mathrm{lbr}$ & $0,9 \mathrm{~cm}$ & $\sqrt{ }$ & $\sqrt{ }$ & $\sqrt{ }$ & $\sqrt{ }$ & $\sqrt{ }$ & $\mathrm{X}$ & - & - & - & - \\
\hline
\end{tabular}




\begin{tabular}{|l|c|c|c|c|c|c|c|c|c|c|c|c|}
\hline \begin{tabular}{l} 
3. Spiral wound tubing \\
\multirow{2}{*}{$\begin{array}{l}\text { /bentuk tabung } \\
\text { (panjang pipa } 25 \mathrm{~cm})\end{array}$}
\end{tabular} & $20 \mathrm{lbr}$ & $0,3 \mathrm{~cm}$ & $\sqrt{ }$ & $\sqrt{ }$ & $\sqrt{ }$ & $\sqrt{ }$ & $\sqrt{ }$ & $\sqrt{ }$ & $\mathrm{x}$ & - & - & - \\
\hline & $30 \mathrm{lbr}$ & $0,6 \mathrm{~cm}$ & $\sqrt{ }$ & $\sqrt{ }$ & $\sqrt{ }$ & $\sqrt{ }$ & $\sqrt{ }$ & $\sqrt{ }$ & $\sqrt{ }$ & $\mathrm{x}$ & - & - \\
\hline & $40 \mathrm{lbr}$ & $0,9 \mathrm{~cm}$ & $\sqrt{ }$ & $\sqrt{ }$ & $\sqrt{ }$ & $\sqrt{ }$ & $\sqrt{ }$ & $\sqrt{ }$ & $\sqrt{ }$ & $\sqrt{ }$ & $\sqrt{ }$ & $\mathrm{x}$ \\
\hline
\end{tabular}

\subsection{Pengembangan Desain Furnitur Anak}

\subsubsection{Identifikasi}

Sebagai gambaran awal dalam pengembangan desain furnitur anak adalah dengan melihat produk sejenis yang ada di pasaran. Dalam penelitian ini, observasi dan wawancara dilakukan di showroom furnitur anak di Jl. Wonosari km. 7 Yogyakarta yang telah beroperasi selama 25 tahun. Selain memproduksi dan menjual furnitur anak, usaha ini juga menyediakan alat peraga edukasi (APE).
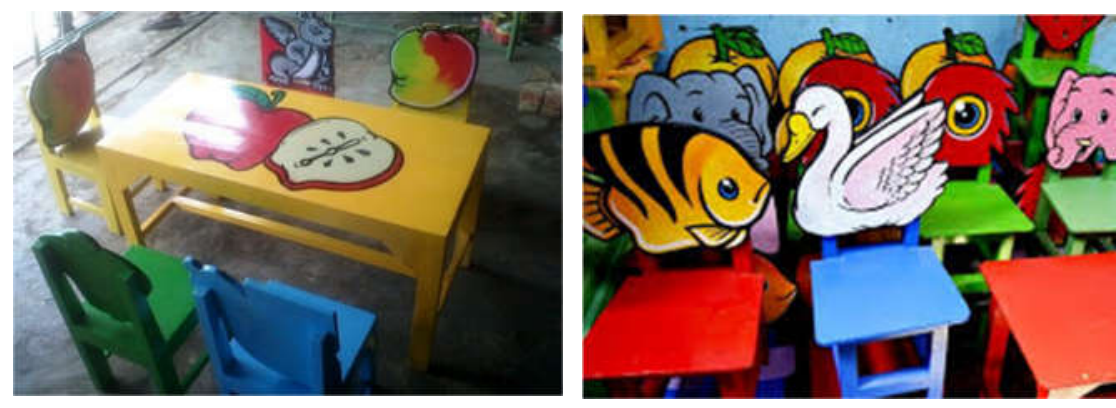

Gambar 4.4. Hasil Survey dan Observasi Produk Furnitur Anak

Sumber : dokumentasi peneliti

Berdasarkan hasil wawancara dengan pemilik usaha, furnitur anak umumnya memakai material kayu dengan warna yang kontras. Sedangkan bentuknya memiliki desain yang sederhana namun berkarakter, seperti bentuk hewan atau buah-buahan. Satu set furnitur anak dijual dengan harga 400 - 500 ribu rupiah, tergantung tingkat kerumitan. Umumnya segmen pembelinya adalah keluarga dan dalam jumlah banyak biasanya dipesan oleh PAUD atau TK.

\subsubsection{Visualisasi}

Dari hasil identifikasi terhadap produk dan pasar maka gagasan pengembangan furnitur anak diterjemahkan menjadi visual dalam bentuk image board dan dikembangkan menjadi sketsa-sketsa gagasan desain. Di bawah ini merupakan image board pengembangan desain furnitur anak berbahan kertas semen bekas. 


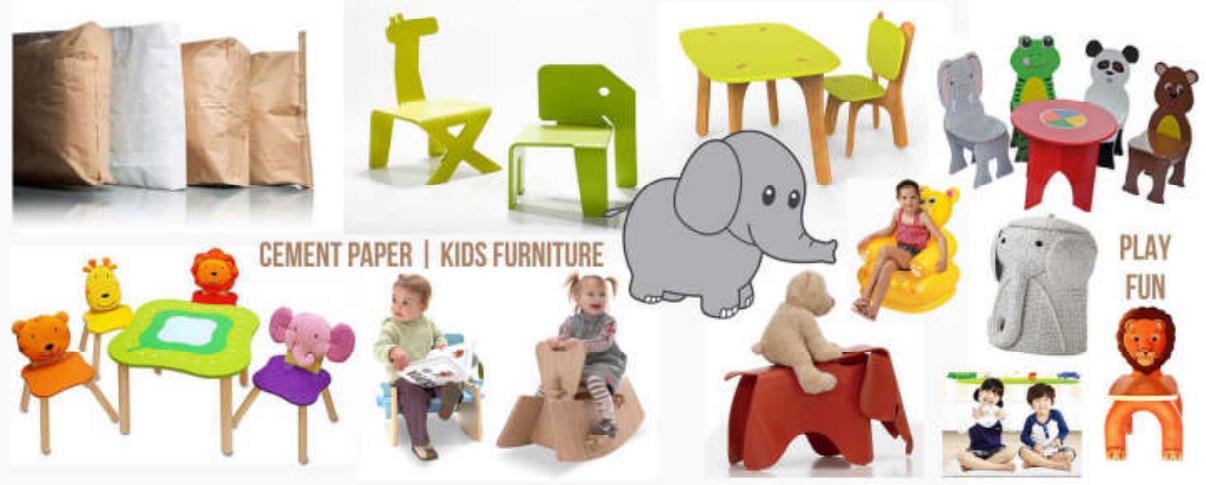

Gambar 4.5. Image board Desain Furnitur Anak berbahan Kertas Semen Bekas

Sumber : kumpulan gambar google.com

Pengembangan desain furnitur anak secara visual melalui sketsa yang mengangkat inspirasi bentuk-bentuk hewan. Anatomi bentuk hewan juga mempermudah proses mimetik dalam desain furnitur karena antara kaki, badan dan kepala bentuknya dapat diserap dalam elemen-elemen dasar furnitur sehingga desain terkesan luchu dan menyerupai mainan anak. Desain furnitur anak juga dikembangkan dalam satu set meja dan kursi agar menyelaraskan bentuk serta menarik minat anak-anak untuk menggunakannya. Sedangkan ukurannya disesuaikan dengan standar kenyamanan meja dan kursi belajar anak kecil usia 3-6 tahun.

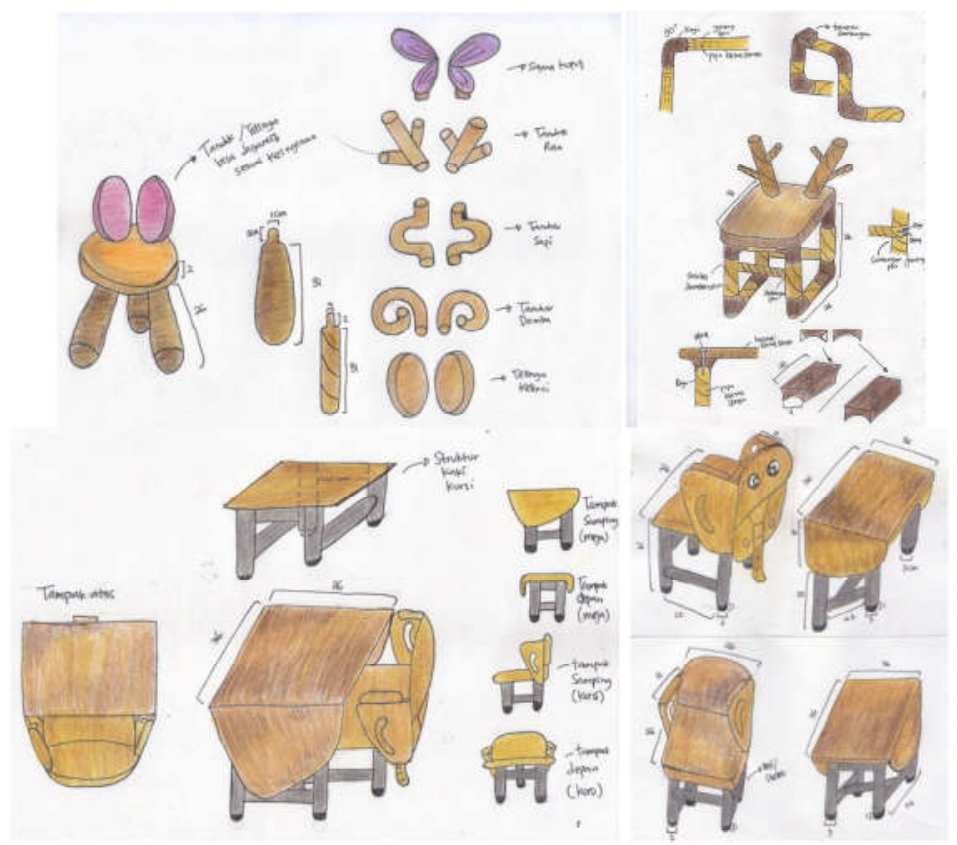

Gambar 4.6. Sketsa-sketsa Pengembangan Desain Furnitur Anak

Sumber : dokumentasi peneliti 
Pengembangan desain secara visual didasari bentuk silinder dan lembaran karena aplikasi dari bentuk dasar hasil eksperimen material kertas semen bekas dengan teknik laminasi dan spiral wound tubing. Sedangkan warna menggunakan warna asli kertas semen bekas, yakni cokelat.

\subsubsection{Materialisasi}

Tahap ini merupakan perwujudan atau mematerialkan gagasan hasil dari proses visualisasi. Proses materialisasi bersifat iteratif atau bersifat menyempurnakan dari beberapa model atau prototype yang dikerjakan. Beberapa langkah yang dilakukan dalam proses materialisasi adalah sebagai berikut :

\section{a. Studi Model Desain Furnitur Anak}

Studi model diperlukan sebagai media untuk mewujudkan secara simulasi ide dari hasil sketsa-sketsa gagasan yang terinspirasi dari bentuk hewan. Proses ini juga merupakan uji coba terhadap perwujudan konsep gagasan karena terdapat beberapa kendala teknis antara sketsa dan model. Studi model dalam penelitian ini (Gambar 4.7.) menghasilkan beberapa bentuk dan penyempurnaannya, antara lain pengembangan desain furnitur anak dengan inspirasi bentuk hewan rusa (gambar a) dan inspirasi bentuk hewan kelinci (gambar c) dan inspirasi bentuk gajah. Objek desain tidak hanya kursi anak namun juga meja belajar untuk mendukung keselarasan desain dalam suatu ruang belajar. Pada pengembangan bentuk hewan rusa (gambar a) struktur penyangga duduk cukup kuat karena menggunakan 4 kaki yang digabungkan menjadi 2 kaki sambungan, namun memiliki kelemahan struktur kekuatan khususnya pada bagian sandaran punggung yang terbagi menjadi beberapa segmen. Dalam pengembangan detail selanjutnya (gambar c), sambungan segmen pada sandaran punggung yang menyerupai tanduk rusa dihilangkan dan dicetak langsung akan tetapi kekuatan strukturnya juga masih kurang. Sedangkan untuk desain furnitur dengan inspirasi hewan kelinci, menggunakan jumlah kaki 3 dan dicoba dengan menggunakan pewarnaan. Bentuk sandaran punggung terinspirasi oleh bentuk telinga kelinci agar memiliki kerapatan yang lebih baik daripada inspirasi bentuk tanduk rusa. 


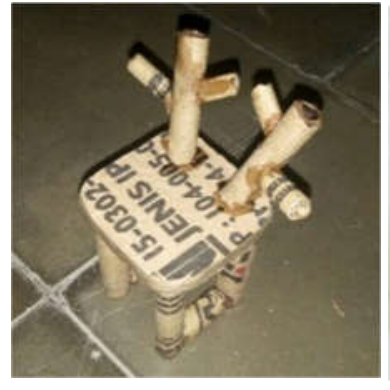

(a)

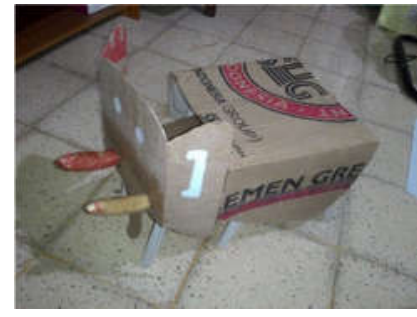

(d)

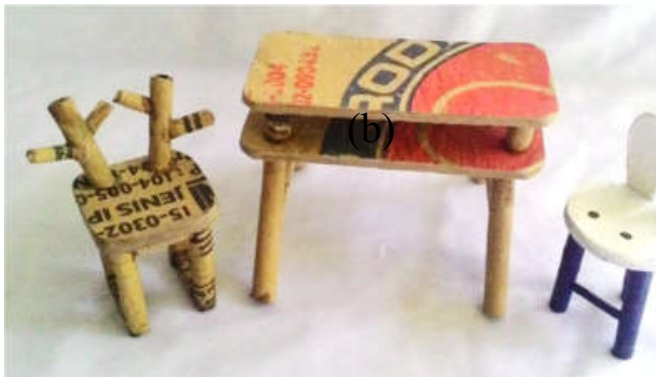

(b)

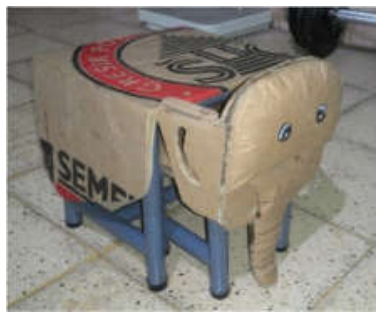

(e)

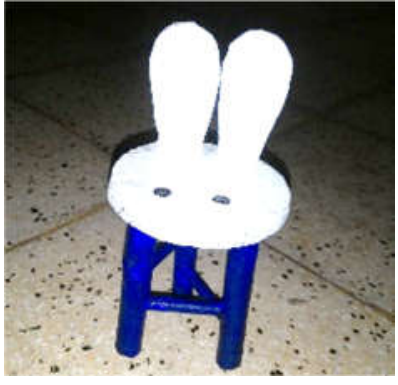

(c)

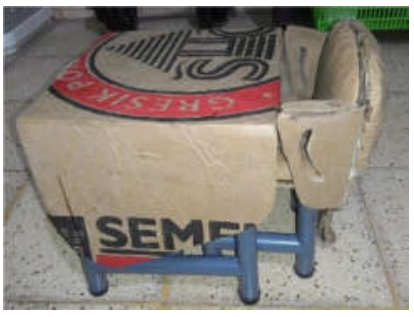

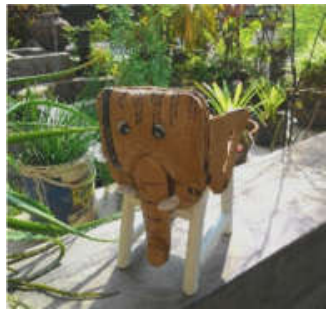

(f)

Gambar 4.7. Studi Model Desain Furnitur Anak berbahan Kertas Semen

Sumber : dokumentasi peneliti

Kedua hasil studi bentuk furnitur anak (gambar a \& c) sama-sama memiliki kelemahan pada sambungan antara alas duduk dan penyangga punggung karena kedua bidang tersebut di saat yang bersamaan akan menerima gaya tekan yang berbeda, yakni ke bawah dan ke belakang. Sedangkan furnitur anak berkaki 4 akan lebih stabil dibanding berkaki 3, meskipun bentuknya terkesan lebih kaku. Pada pengembangan bentuk furnitur dengan inspirasi hewan gajah (gambar $\mathrm{d}$ - f), bentuk meja disesuaikan dengan anatomi bentuk tubuh gajah sehingga antara meja dan kursi memiliki kesinambungan bentuk yang kuat dan selaras. Optimalisasi fungsi pada inspirasi bentuk juga terdapat pada bentuk sandaran tangan yang menyerupai bentuk telinga gajah. Berdasarkan hasil studi model desain furnitur anak berbahan kertas semen bekas, maka pengembangan bentuk lebih berfokus pada penyesuaian dan penyelarasan antara fungsi meja/kursi dan inspirasi bentuk hewan, salah satu inspirasi hewan yang dikembangkan adalah bentuk gajah.

\section{b. Studi Sistem Sambungan Furnitur Anak}

Pemilihan bentuk sambungan yang tepat akan menambah kekuatan furnitur dalam menahan beban pengguna, maka sebelum merealisasikan desain furnitur anak dengan ukuran 1:1 diperlukan studi terhadap beberapa bentuk dan jenis sambungan 
menggunakan berbahan kertas semen bekas dengan teknik laminasi atau spiral wound tubing. Di bawah ini (gambar 4.8.) merupakan hasil dari pengembangan berbagai bentuk sambungan berbahan kertas semen bekas. Pada pengembangan bentuk sambungan pertama menggunakan bentuk seperti pada pipa atau paralon air dengan teknik spiral wound tubing (gambar a dan b), namun kelemahan dari model sambungan ini selain tidak cukup kuat jika ditarik, juga proses pembuatannya yang memakan waktu lama. Model sambungan berikutnya (gambar c) mengembangkan model pen atau seperti pada furnitur bambu, yakni diameter pipa yang besar ditusuk oleh pipa yang lebih kecil kemudian diberi perekat. Pada gambar $\mathrm{d}$ - $\mathrm{f}$ merupakan pengembangan dari sistem pen, namun dengan bentuk penusuk yang berbeda-beda. Model pen lebih memudahkan pembuatan sambungan karena tidak perlu mencetak sambungan terlebih dahulu, namun tidak dapat dibongkar pasang.

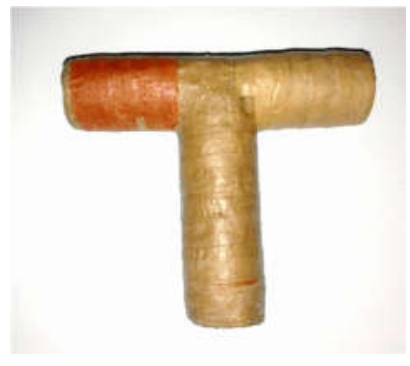

(a)

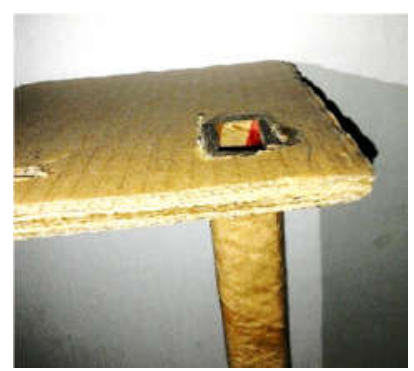

(d)

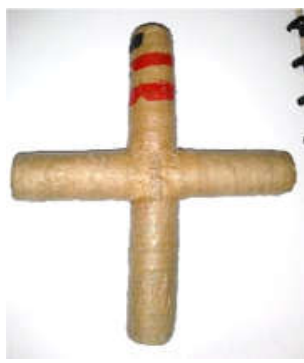

(b)

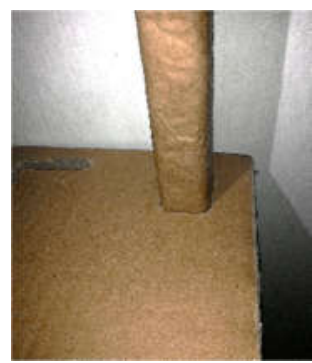

(e)

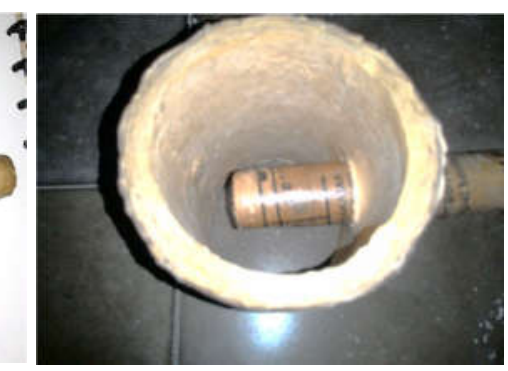

(c)

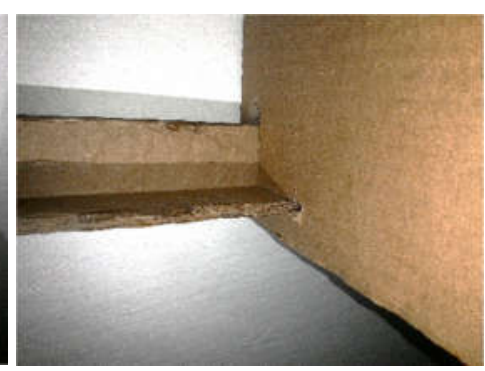

(f)

Gambar 4.8. Studi Model Desain Furnitur Anak berbahan Kertas Semen

Sumber : dokumentasi peneliti

Berdasarkan proses studi bentuk dan studi sambungan, maka dalam pengembangan desain furnitur anak berbahan kertas semen bekas dengan teknik laminasi dan spiral wound tubing memerlukan kombinasi bahan lain untuk memperkuat sambungan khususnya antara bagian tempat duduk dengan sandaran punggung yang sangat rawan patah. Bahan kombinasi yang dipakai adalah besi yang diaplikasikan 
sebagai penguat sambungan pada kursi dan meja. Selain sebagai penguat sambungan, kombinasi pipa besi juga menambah kesan dinamis pada furnitur anak. Pada bagian yang tidak menahan beban besar, tetap menggunakan model sambungan pen.

\section{c. Prototype Desain Pengembangan Furnitur Anak berbahan Kertas Semen Bekas}

Setelah melakukan studi model dan studi terhadap bentuk sambungan maka tahap berikutnya adalah memilih dan merealisasikan gagasan berdasarkan hasil studi tersebut. Pengembangan desain furnitur anak dipilih dengan mengadopsi bentuk gajah sebagai inspirasi agar furnitur lebih menarik minat anak untuk memakai. Sedangkan ukuran dari furnitur ini menyesuaikan standar ergonomi dari anak usia 4-6 tahun dengan ketinggian alas duduk $30 \mathrm{~cm}$. Penerapan teknik laminasi digunakan pada alas meja dan kursi, sedangkan teknik spiral wound tubing digunakan pada kaki-kakinya. Penyelesaian akhir (finishing) dari furnitur anak ini tidak menggunakan pewarna atau cat sehingga konsep daur ulang dapat muncul dan mudah dikenali pada produk.
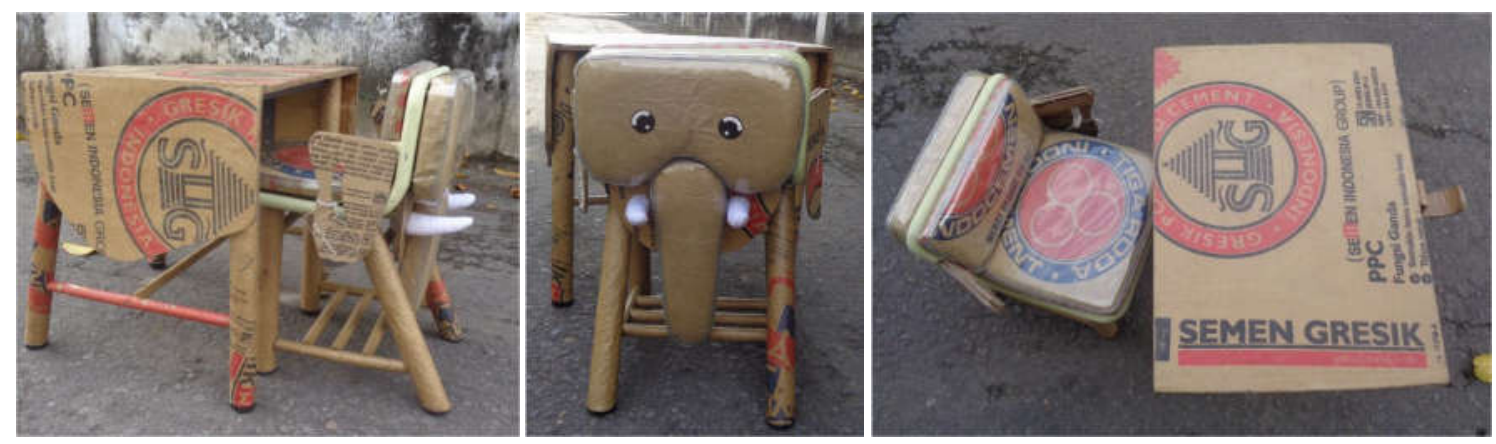

Gambar 4.9. Prototype Desain Furnitur Anak berbahan Kertas Semen Bekas

Sumber : dokumentasi peneliti

\subsection{Uji coba dan Evaluasi Produk Furnitur Anak}

Proses uji coba produk dilakukan kepada bakal pengguna produk yakni anak-anak berusia 4-6 tahun dalam beraktifitas normal, seperti belajar, membaca, mewarnai, dll. Hal ini dilakukan untuk mendapat data dan informasi terkait dengan kekuatan struktur produk, kenyamanan dan keindahan bentuk secara visual. Pada saat uji coba anak-anak dibebaskan untuk langsung berinteraksi dengan produk, anak-anak terlihat tertarik pada pada desain furnitur yang menyerupai hewan gajah serta langsung dapat memahami bentuk dan fungsinya baik meja maupun kursi. Anak anak merasa nyaman dan senang memakai meja kursi tersebut karena bentuk dan material yang unik. Orang tua dan guru anak-anak juga tertarik dengan konsep furnitur berbahan kertas semen bekas yang dapat menjadi objek riil dari pemanfaatan bahanbahan bekas di lingkungan sekitar. Berdasakan hasil uji coba dan evaluasi, maka terdapat 
penambahan detail desain pada bagian belakang meja yang diberi gantungan kecil menyerupai ekor untuk menggantungkan tas belajar anak-anak.
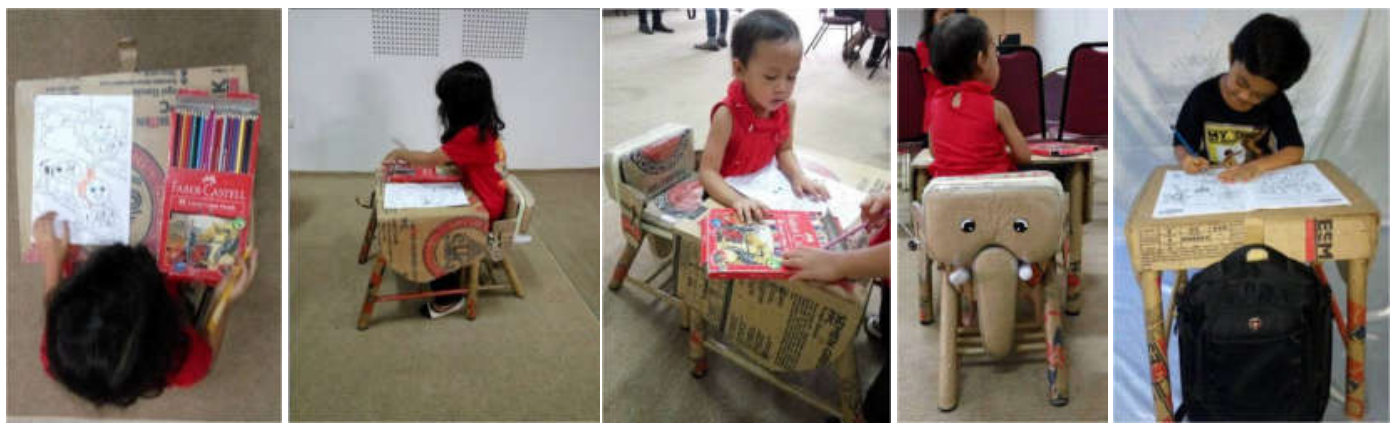

Gambar 4.9. Uji Coba Desain Furnitur Anak berbahan Kertas Semen Bekas

Sumber : dokumentasi peneliti

Sedangkan dalam hal komersial, harga produksi satu set furnitur berbahan kertas semen bekas adalah 330 ribu rupiah, hal ini cukup terjangkau dan lebih murah dibandingkan dengan furnitur anak berbahan kayu yang berkisar antara 400 hingga 500 ribu rupiah.

\section{Kesimpulan}

Material kertas semen bekas yang diolah dengan teknik laminasi dan spiral wound tubing merupakan bahan dasar alternatif dalam pembuatan furnitur anak. Kekuatannya telah teruji mampu menahan beban statis sebesar 50 kilogram yang setara dengan beban tubuh anak-anak dan ketika diaplikasikan menjadi sebuah kursi juga mampu menahan beban dinamis dari pergerakan anak (pengguna) saat duduk dan beraktifitas. Sedangkan sistem dan bentuk sambungan antara papan laminasi kertas semen bekas dengan gulungan juga belum dapat dioptimalkan secara kekuatan sehingga pada sambungan masih memerlukan material pipa besi untuk memperkuat dan meningkatkan kualitas visual pada desain furnitur anak. Meskipun memerlukan material pelengkap akan tetapi penerapan material kertas semen bekas pada desain furnitur tetap menjadi material utama. Melalui penelitian dan pengembangan desain ini, kertas semen bekas memiliki satu inovasi dalam pengolahan material sehingga mampu meningkatkan nilai komersial kertas semen bekas yang dijual per kilogram sebelum diolah. Sedangkan dari segi pasar produk, orang tua dan guru tertarik dengan keunikan material dan bentuk dari furnitur kertas semen bekas. Dengan harga produksi satuan dalam penelitian ini, satu set furnitur dapat dijual dengan harga yang lebih murah dengan furnitur berbahan kayu yang ada di pasaran. 
Salah satu konfigurasi bentuk yang tepat sebagai desain furnitur anak adalah dengan mengadopsi bentuk hewan sebagai inspirasi, sehingga pengembangan desain tidak hanya bentuk gajah, namun dapat juga hewan lain seperti badak, jerapah, singa, kuda, dll. Pengembangan desain furnitur berbahan kertas semen bekas juga tidak terbatas pada segmen anak-anak, namun dapat ditujukan untuk segmen dewasa.

\section{Daftar Pustaka}

[1] APKI (2014). Tantangan Dan Peluang Industri Pulp Dan Kertas Menghadapi Masyarakat Ekonomi ASEAN-2015. Bulletin APKI. Edisi Januari-April 2014, pp. 7-10.

[2] Asbhy, M. \& Johnson, K. (2010). Materials and Design:The Art and Science of Material Selection in Product Design. Oxford. Elsevier

[3] Atnam, R. (2007). Jenis Dan Kualitas Serat Berdasarkan Komposisi Serat. Institut Pertanian Bogor. Bogor

[4] Gegadannitisswari, G. (2009). Perencanaan dan Perancangan Interior Pendidikan Prasekolah Nasional Plus di Surakarta. Skripsi Fakultas Sastra dan Seni Rupa. Universitas Sebelas Maret, Solo.

[5] Handayani, S. (2009). Metode Perekatan Dengan Lem Pada Sambungan Pelebaran Kayu. Jurnal Teknik Sipil dan Perencanaan (UNS). Volume 11-No. 1 Januari 2009, pp.11-20.

[6] Leonel, R., Gazali, W. \& Manik, N. (2008). Optimalisasi Produksi Paper Tube menggunakan Metode Dynamic Programming, Jurnal Mat Stat. Universitas Bina Nusantara Vol. 8 No. 1, Januari 2008, pp. 44-59.

[7] Saragi, D. (2008). Pembuatan dan Karakterisasi Kertas Pembungkus yang dibuat dari Kantong Semen Bekas dengan Pulp Jerami. Tesis Sekolah Pasca Sarjana Universitas Sumatera Utara, Medan.

[8] Sihombing, B. (2009). Pembuatan dan Karakterisasi Batako Ringan yang dibuat dari Sludge (Limbah Padat) Industri Kertas - Semen. Tesis Sekolah Pasca Sarjana Universitas Sumatera Utara, Medan.

[9] Walker, J. (2006). Primary Wood Processing, Principles, and Practice. Springer. New Zealand. 